\title{
THE DETERMINATION OF THE POSSIBILITY OF OBTAINING OF AN ADHESIVE ADDITIVE TO ROAD BITUMEN PRODUCED FROM LIQUID PRODUCTS OF COAL COKING USING CARBAZOLE
}

(C) Yu.V. Prysiazhnyi, PhD in technical sciences, S.V. Pyshyev, Doctor of Technical Sciences, Guri Isaiah, postgraduate, T.I. Chervinskyy, PhD in chemical sciences, B.O. Korchak, PhD in technical sciences (Lviv Polytechnic Naional University, 12 Stepan Bandera Str., 79013, Lviv, Ukraine)

Coumarone-indene resins (CIR) have been obtained from a narrow coumarone-indene fraction by ionic cooligomerization. To improve the adhesion properties of CIR, nitrogen-containing functional groups have been additionally introduced into them at the stage of synthesis. The positive effect of carbazole on the degree of polymerization of styrene, coumarone and indene was noted. The products obtained (coumarone-indenecarbazole resins - CICR) have been used as modifiers for the road oil bitumen. The analysis of physical and technological indicators of the original and modified bitumen has been carried out in accordance with the standardized methods. The influence has been investigated of the temperature of separation of the unreacted part of the raw material from the CICR on its qualitative characteristics. It has been experimentally proved that the unreacted raw material is completely separated from the resin at a distillation temperature of about $150{ }^{\circ} \mathrm{C}$.

The experimental data obtained indicates that CIR, in comparison with CICR, due to its own high softening temperature, increases the same indicator of modified bitumen, however, this effect is achieved when the resin content in the bitumen is too high, namely $\geq 3.0-5.0 \%$ by mass. At the same time, the addition of CIR to bitumen worsens it ductility and penetration. Adhesion is significantly improved, but again with the mass content of CIR in the mixture at the level of 3.0-5.0\% and more.

The use of CICR as a modifier showed that this resin has practically no effect on the softening temperature and has a less negative effect on bitumen ductility and penetration, than CIR. At the same time, a positive effect has been observed in relation to the adhesion to glass - this indicator significantly increases even at a mass content of resin in bitumen at the level of 0.5-1.0\%. Thus, coumarone-indene-carbazole resins should be used as an adhesive additive that has a positive effect only on the adhesion of bitumen to a solid surface.

In order to improve CIR adhesive properties, nitrogen-containing functional groups were additionally introduced into them at the synthesis stage. The resulting products (coumarone-indene-carbazole resins - CICR) were used as modifiers for road petroleum bitumen. The influence of the temperature of separation of raw materials unreacted part from CICR on its qualitative characteristics was investigated. It was established that the key effect of adding CICR to bitumen is the improvement of adhesive properties of the obtained bituminous-polymeric materials.

Keywords: liquid products of coal coking, cooligomerization, carbazole, resin, modifier, bitumen, adhesive properties. 